\title{
The Preparation of CNTs/PE Nanocomposites Particles with Coral Shape and Core-Shell Structure In Situ Produced via Nanotemplate Catalyst Based on MWCNTs
}

\author{
Jing Wang ${ }^{1}$, Jiangping Guo', Yang Zhou', Qigu Huang ${ }^{1 *}$, Jianjun $\mathrm{Yi}^{2}$, Hongming $\mathrm{Li}^{2}$, Yunfang Liu' ${ }^{1}$ Kejing Gao ${ }^{2}$ and Wantai Yang ${ }^{1}$
}

${ }^{1}$ State Key Laboratory of Chemical Resource Engineering, Key Laboratory of Carbon Fiber and Functional Polymers, Ministry of Education, Beijing University of Chemical Technology, People's Republic of China

${ }^{2}$ Lab for Synthetic Resin Research Institution of Petrochemical Technology, China National Petroleum Corporation, People's Republic of China

\begin{abstract}
A kind of nano template catalyst was prepared through loading the active compound $\left(\mathrm{m}-\mathrm{CH}_{3} \mathrm{PhO}\right) \mathrm{TiCl} 3$ on carbon nanotubes (CNTs). This catalyst can catalyze (co)polymerization of ethylene to form CNTs/polyethylene (PE) nanocomposites particles. The nano template catalyst showed high catalytic activity up to $5.8 \mathrm{~kg} /(\mathrm{gTi}$.h.p) for the copolymerization of ethylene with 1-hexene. The results revealed that the nascent CNTs/PE nanocomposites particles looked like coral shape and featured with the core-shell structure which CNTs as the core and polyethylene as the shell.
\end{abstract}

Keywords: Carbon nanotubes; Nanocomposites; Microstructure

\section{Introduction}

Porous materials such as $\mathrm{SiO}_{2}, \mathrm{MgCl}_{2}$ and $\mathrm{Al}_{2} \mathrm{O}_{3}$ have been applied as supports for heterogeneous Ziegler-Natta catalysts in olefins polymerization. Many reports on the use of porous materials as supports for Ziegler-Natta catalysts, metallocene catalysts and nickel diimine catalysts in the olefin polymerization have appeared in the literature [1-8].

Carbon materials have been attracted much attention on promising fillers in various polymers because of their excellent mechanical, thermal and electrical properties. Carbon nanofibers [9] and graphene oxide [10] are treated with methylaluminoxane and then loaded the active species on the surface for ethylene/propylene polymerization. All most previous works report that the efficient active sites are directly anchored on the supports surface without chemical bond between the active site and the support. Zhu [11] utilized two methods for the impregnation of Ni-diimine complexes on silicatebased nanotubes, which were carried out for ethylene polymerization. Wanke [12] studied the morphology of polyethylene particle catalyzed by $\mathrm{MgCl}_{2}$-supported Ziegler-Natta catalyst. He found that the polymer particle was a perfect replica of the catalyst particle. The obtained milli-scaled polyethylene particles were spherical. Young [13] used a thermally pretreated bimetallic $\mathrm{MgCl}_{2}$ /tetrahydrofuran (THF)/ $\mathrm{TiCl}_{4}$ catalyst for producing polyethylene particles with regular and homogeneous globule. Mao [14,15] developed $\mathrm{MgCl}_{2}$-supported Ziegler-Natta catalysts for ethylene and propylene polymerization to produce the polymer particles with good spherical morphology. Choi [7] synthesized $\mathrm{MgCl}_{2}$-supported nickel diimine catalysts for ethylene polymerization with high catalytic activity, and the obtained polymer particles had good spherical morphology. Kanellopoulos [16] studied the single particle growth in heterogeneous olefin polymerization according to the random pore polymeric flow model. Our previous work [8] reported that $\mathrm{MgCl}_{2}$-supported Ziegler-Natta catalysts with different structure ligands had efficient catalytic activity for the copolymerization of ethylene with 1-octene. The comonomer incorporation content of the copolymer was relative to the catalysts' ligand structure. Carbon nanotubes (CNTs) have been attracted much attention because of their excellent mechanical, thermal and electrical properties. Based on these distinctive advantages, they were considered to be promising fillers in various polymers. Huang [10] prepared the polypropylene/graphene oxide nanocomposites by in situ ZieglerNatta polymerization. The active site $\mathrm{TiCl}_{4}$ was anchored to the support graphene oxide through $\mathrm{MgCl}_{2}$. Milani [17] obtained polypropylene (PP)/graphene nanosheet (GNS) nanocomposites with good molecular weight, thermal properties, and tacticity by in situ polymerization using metallocene catalysts. Kaminsky [9] reported that carbon black (CB), carbon nanofibers (CNFs) and different types of CNTs were separated by ultra sound and then treated with methylaluminoxane (MAO). These catalytic active centers efficiently promoted ethylene/ propylene polymerization and polyolefin nanocomposites were obtained after mixing zirconocenes or other transition metal complexes with the fillers. Pinheiro [18] prepared linear low-density polyethylene nanocomposites containing different types of nanofiller $\left(\mathrm{TiO}_{2}\right.$, MWCNT, expanded graphite, and boehmite) by in situ polymerization using a Zirconium-Nickel tandem catalyst system. All most previous works reported that the efficient active sites were directly anchored on the supports surface without chemical bond between the active site and the support. The active sites included $\mathrm{TiCl}_{4}$, metallocene catalysts, $\alpha$ and $\beta$-diimine complexes, FI catalyst, $\mathrm{Cr}$-based catalyst and et al. The supports included $\mathrm{MgCl}_{2}, \mathrm{SiO}_{2}$, carbon nanotubes; graphene oxide and et al. Recently, Wang [19] reveal that the active site $\mathrm{TiCl}_{4}$ is directly bonded with the support oxidized nanosized carbon spheres through Ti-O bond. Coperet [20] investigated $\mathrm{SiO}_{2}$-supported dinuclear CrIII sites to polymerize olefins forming polymers initiated by $\mathrm{C}-\mathrm{H}$ bond activation, the active site is directly bonded with the support through Cr-O-Si bond.

${ }^{*}$ Corresponding author: Qigu Huang, State Key Laboratory of Chemica Resource Engineering, Key Laboratory of Carbon Fiber and Functional Polymers, Ministry of Education, Beijing University of Chemical Technology, Beijing 100029, People's Republic of China, Tel: +86-10-64433856; Fax: +86-10-64433856; E-mail: huangqg@mail.buct.edu.cn

Received April 10, 2015; Accepted May 28, 2015; Published May 05, 2015

Citation: Wang J, Guo J, Zhou Y, Huang Q, Jianjun Yi, et al.(2015) The Preparation of CNTs/PE Nanocomposites Particles with Coral Shape and Core-Shell Structure In Situ Produced via Nanotemplate Catalyst Based on MWCNTs. J Adv Chem Eng 5: 124. doi:10.4172/2090-4568.1000124

Copyright: ( 2015 Wang $\mathrm{J}$ et al. This is an open-access article distributed under the terms of the Creative Commons Attribution License, which permits unrestricted use, distribution, and reproduction in any medium, provided the original author and source are credited. 
Citation: Wang J, Guo J, Zhou Y, Huang Q, Jianjun Yi, et al.(2015) The Preparation of CNTs/PE Nanocomposites Particles with Coral Shape and Core-Shell Structure In Situ Produced via Nanotemplate Catalyst Based on MWCNTs. J Adv Chem Eng 5: 124. doi:10.4172/20904568.1000124

Page 2 of 5

In this work, we report that the CNTs/PE nanocomposites particles with the coral-shaped and core-shell structure in situ produced by the nano template catalyst $\left(m-\mathrm{CH}_{3} \mathrm{PhO}\right) \mathrm{TiCl}_{3} / \mathrm{CNTs}$ which is directly bonded to the oxidized multiwalled carbon nanotubes (MWCNTs) through Ti-O bond, $\mathrm{AlEt}_{3}$ used as a co-catalyst. The morphology and structure of the nano template catalyst and the obtained CNTs/ $\mathrm{PE}$ nanocomposites particles, as well as the performance of the polymerization, are investigated.

\section{Experimental Section}

\section{General remarks}

All operations of air- and moisture-sensitive materials were performed using the rigorous repellency of oxygen and moisture in flamed Schlenk-type glassware on a dual manifold Schlenk line under a nitrogen atmosphere. $\mathrm{CH}_{3} \mathrm{MgCl}$ with $22 \mathrm{wt} \%$ in tetrahydrofuran (THF) and triethylaluminum ( $\mathrm{AlEt}_{3}$ ) with $1.0 \mathrm{M}$ in hexane were purchased from Acros Organics Agent in China. $\mathrm{MgCl}_{2}$ (water included $<0.01 \%$ ), $\operatorname{AlEt}_{3}$ (2.0 $\mathrm{M}$ in $\mathrm{n}$-hexane) and $m$-cresol were purchased from Acros in China. 1-hexene were from Fluka in China. Other chemicals were from Beijing chemical agent company. 3-Chloro-1,2-epoxypropane and tributyl phosphate were treated with activated $5 \AA$ molecular sieves under high-purity nitrogen for one week before use. Toluene, THF and $\mathrm{n}$-hexane were further purified by refluxing over metal sodium under nitrogen for $48 \mathrm{~h}$ and distilled before use. Ethylene (polymerization grade) was from Sino-petrochemical Company, and used without further purification.

\section{Synthesis of non-metallocene catalyst}

To a stirred solution of $\mathrm{TiCl}_{4}(11.0 \mathrm{~mL}, 0.10 \mathrm{~mol})$ in toluene $(30$ $\mathrm{mL})$, one equivalent of $m$-cresol $(10.5 \mathrm{~mL}, 0.10 \mathrm{~mol})$ was added with a syringe at $-25^{\circ} \mathrm{C}$. The mixture was gradually warmed to $30^{\circ} \mathrm{C}$ for 4 $\mathrm{h}$. The mixture was filtrated and extracted by toluene. The solvent was removed, brown solid $\left(m-\mathrm{CH}_{3} \mathrm{PhO}\right) \mathrm{TiCl}_{3}$ was obtained with yield 22.40 g (89.6\%). ( $\left.m-\mathrm{CH}_{3} \mathrm{PhO}\right) \mathrm{TiCl}_{3}\left(\mathrm{M}_{\mathrm{w}}=261.3\right)$ compound: ${ }^{1} \mathrm{H}$ NMR: $\delta 7.13$ (tri, $1 \mathrm{H}), \delta 6.75(\mathrm{~m}, 1 \mathrm{H}), \delta 6.65(\mathrm{~m}, 2 \mathrm{H}), 2.30(\mathrm{~s}, 3 \mathrm{H})$; ELEM.ANAL, Calcd: C, 32.12; H, 2.68. Found: C, 32.20; H, 2.59. ${ }^{13} \mathrm{C}$ NMR: $\delta 169.54$ (C1), 119.42 (C2), $\delta 139.57$ (C3), $\delta 126.71$ (C4), $\delta 128.92$ (C5), $\delta 115.96$ (C6), $\delta 21.18\left(\mathrm{CH}_{3}\right)$.

\section{Preparation of oxidized MWCNTs}

Two grams $(2.0 \mathrm{~g})$ MWCNTs and $100 \mathrm{~mL}$ of concentrated nitric acid were added into a $250 \mathrm{~mL}$ Schlenk flask. The mixture was subjected to ultrasonic washing for $5 \mathrm{~min}$ with an ultrasonic washer and was stirred for $5 \mathrm{~h}$ with a stirring bar at $80^{\circ} \mathrm{C}$. The obtained residue after filtrating was washed twice with distilled water and anhydrous ethanol, respectively, and then it was further purified by vacuum for $1 \mathrm{~h}$ to obtain black bulk solid, oxidized MWCNTs with diameter of 50 $\mathrm{nm}$ and length of $c a 20 \mu \mathrm{m}$. The yield was $1.70 \mathrm{~g}$.

\section{Preparation of MWCNTs supported catalyst}

Oxidized MWCNTs $(1.5 \mathrm{~g})$ and $\mathrm{n}$-hexane $(100 \mathrm{~mL})$ were added into a $250 \mathrm{~mL}$ schlenk flask. The mixture was stirred in high speed with a dripping of $21.0 \mathrm{~mL}$ of $\mathrm{CH}_{3} \mathrm{MgCl}(0.06 \mathrm{~mol})$. The reaction was carried out for $2 \mathrm{~h}$ at room temperature, the reactant was filtrated and the residue was washed twice with $50 \mathrm{~mL}$ of $\mathrm{n}$-hexane to remove the remnant Grignard reagent. The obtained solid and $50 \mathrm{~mL}$ of $\mathrm{n}$-hexane were added into a $250 \mathrm{~mL}$ schlenk flask, followed by adding $15.0 \mathrm{~g}$ of $\left(m-\mathrm{CH}_{3} \mathrm{PhO}\right) \mathrm{TiCl}_{3}$ at $0^{\circ} \mathrm{C}$. Then the reaction system was stirred for 1 $\mathrm{h}$ at the same temperature. Warming to $60^{\circ} \mathrm{C}$ slowly, the mixture was maintained for $2 \mathrm{~h}$ at $60^{\circ} \mathrm{C}$. After that, the reaction system was filtrated.
The residue was washed in turn with toluene and n-hexane $(50 \mathrm{~mL}$ each time) at $50^{\circ} \mathrm{C}$ until no titanium in the filtrate was determined by Inductively Coupled Plasma (ICP) and drying under vacuum for $2 \mathrm{~h}$. Black powder product was obtained with yield of $1.83 \mathrm{~g}$. The titanium content of the catalyst was $4.0 \mathrm{wt} \%$ confirmed by ICP, i.e. $\left(m-\mathrm{CH}_{3} \mathrm{PhO}\right)$ $\mathrm{TiCl}_{3}$ content was $21.8 \mathrm{wt} \%$. The number of the active sites on CNTs presented with $\left(m-\mathrm{CH}_{3} \mathrm{PhO}\right) \mathrm{TiCl}_{3}$ was $63 \%$, estimated by the result of the poisoning experiment according to the literature [21].

\section{Preparation of $\mathrm{MgCl}_{2}$ supported catalyst}

The supported catalyst $\left(m-\mathrm{CH}_{3} \mathrm{PhO}\right) \mathrm{TiCl}_{3} / \mathrm{MgCl}_{2}$ was prepared according to the literature [8]. To a mixing solution of $\mathrm{MgCl}_{2}$ (solid, $1.0 \mathrm{~g})$ dissolved in toluene $(60 \mathrm{~mL}), 3$-chloro-1,2-epoxypropane and tributyl phosphate, $11.0 \mathrm{~g}$ of $\left(m-\mathrm{CH}_{3} \mathrm{PhO}\right) \mathrm{TiCl}_{3}$ in toluene $(\mathrm{Mg}: \mathrm{Ti}=1: 4$ in mol ) were added by a syringe at $-10^{\circ} \mathrm{C}$ over a period of $1 \mathrm{~h}$ in a 300 $\mathrm{mL}$ Schlenk flask with a magnetic bar. Then the mixture was enhanced to $60^{\circ} \mathrm{C}$ and kept it for $3 \mathrm{~h}$ at the temperature. Adding n-hexane 20 $\mathrm{mL}$, spherical precipitate was given. The mixture was filtrated and washed in turn with toluene and $\mathrm{n}$-hexane for times ( $40 \mathrm{~mL}$ each time) at $50^{\circ} \mathrm{C}$ until no titanium in the filtrate was determined by ICP, then dried by vacuum. Spherical catalyst particles were obtained in yield of $1.31 \mathrm{~g}$ with brown color. The titanium content of the catalyst was 3.8 wt $\%$, as determined by ICP analysis, i.e. $\left(m-\mathrm{CH}_{3} \mathrm{PhO}\right) \mathrm{TiCl}_{3}$ content was $20.7 \mathrm{wt} \%$. The number of the active sites on CNTs presented with $\left(m-\mathrm{CH}_{3} \mathrm{PhO}\right) \mathrm{TiCl}_{3}$ was $51.6 \%$ which was also estimated according to the literature [21].

\section{Polymerization procedure}

All polymerizations were carried out in a $2000 \mathrm{~mL}$ stainless steel reactor equipped with a magnetic stirrer after purging all moisture and oxygen by a high-vacuum pump, the reactor was sealed under a nitrogen atmosphere. Freshly distilled hexane $(1000 \mathrm{~mL})$, along with the desired amounts of heterogeneous non-metallocene catalyst and $\mathrm{AlEt}_{3,}$, were added in the order. The mixture was stirred for $15 \mathrm{~min}$ for preactivation, and heating to $80^{\circ} \mathrm{C}$, comonomer 1-hexene was charged into the reactor and the copolymerization was initiated by the introduction of ethylene and ethylene pressure was kept at $0.2 \mathrm{MPa}$ for a desired time. The monomer pressure was kept constant during the polymerization by continuously charging with ethylene. The reaction was stirred for a desired time. Finally, the polymerization was terminated with $10 \mathrm{wt} \% \mathrm{HCl}$ in alcohol. The obtained polymer was filtered, washing with alcohol and water, and then drying overnight in a vacuum oven at $50^{\circ} \mathrm{C}$. Ethylene consumption was automatically recorded by a flowmeter. Ethylene polymerization followed the same procedure, but there was no comonomer added.

\section{Characterization}

${ }^{13} \mathrm{C}$ NMR spectra were recorded on an INOVA500 MHz instrument operating at $125 \mathrm{MHz}$. The condition used for quantitative ${ }^{13} \mathrm{C}$ NMR was of the copolymer content up to $15 \mathrm{wt} \%$ in solution, using orthodichlorobezene $\left(d_{4}\right)$ as the solvent at $125^{\circ} \mathrm{C}$. Tetramethylsilane was used as internal chemical shifts reference. The 1-hexene incorporation was estimated from ${ }^{13} \mathrm{C}$ NMR spectra according to the literature [22-24]. The average molecular weight and molecular weight distribution were measured by a PL-GPC220 instrument using standard polystyrene as a reference and 1,2,4-trichlorobenzene as a solvent at $150^{\circ} \mathrm{C}$. DSC thermograms were recorded with a PA5000-DSC instrument at a rate of $10 \mathrm{~K} / \mathrm{min}$. Scanning electron microscopy (SEM), morphological observation for the catalyst particle and polymer particle was performed on SUPRA 55/55VP field emission scanning electron microscope. The samples (the catalyst particle and polymer particle) for SEM were 
Citation: Wang J, Guo J, Zhou Y, Huang Q, Jianjun Yi, et al.(2015) The Preparation of CNTs/PE Nanocomposites Particles with Coral Shape and Core-Shell Structure In Situ Produced via Nanotemplate Catalyst Based on MWCNTs. J Adv Chem Eng 5: 124. doi:10.4172/20904568.1000124

obtained by immobiled on a film, and were sputter coated with gold to c.a. $15 \mathrm{~nm}$ thicknesses. Micrographs were taken at $20 \mathrm{kV}$ HR-TEM. The titanium content in the catalyst was determined using a Shimadzu ICPS-5000 inductively coupled plasma emission spectrometer. ${ }^{1} \mathrm{H}$ NMR spectra was measured on an INOVA500MHz instrument. ${ }^{1} \mathrm{H}$ chemical shifts were reported in ppm relative to proton resonance in chloroform-d at $\delta 7.26 \mathrm{ppm}$. Elemental analyses were performed on a Perkin-Elmer 2400 microanalyzer at the College of Material Science and Technology, Beijing University of Chemical Technology.

\section{Results and Discussion}

\section{Properties of the heterogeneous nano template catalyst}

The kinetic curves of the catalyst $\left(m-\mathrm{CH}_{3} \mathrm{PhO}\right) \mathrm{TiCl}_{3} / \mathrm{CNTs}, \mathrm{AlEt}_{3}$ used as a cocatalyst, for the copolymerization of ethylene with 1-hexene is shown in Figure 1. From Figure 1a, the catalyst $\left(m-\mathrm{CH}_{3} \mathrm{PhO}\right) \mathrm{TiCl}_{3} /$ CNTs exhibited much higher catalytic activity than that of catalyst $\left(m-\mathrm{CH}_{3} \mathrm{PhO}\right) \mathrm{TiCl}_{3} / \mathrm{MgCl}_{2}$. The catalytic activity of the catalyst system $\left(m-\mathrm{CH}_{3} \mathrm{PhO}\right) \mathrm{TiCl}_{3} / \mathrm{CNTs} / \mathrm{AlEt}_{3}$ maintains nearly constant at $80^{\circ} \mathrm{C}$ over $2 \mathrm{~h}$ even at fairly low titanium concentration, such as $5.4 \times 10^{-5}$ $\mathrm{M}$ in $1000 \mathrm{~mL}$ of solvent. The polymer mass increases linearly with increasing polymerization time within $2 \mathrm{~h}$ (Figure 1a'). The results indicate that the catalyst $\left(m-\mathrm{CH}_{3} \mathrm{PhO}\right) \mathrm{TiCl}_{3} / \mathrm{CNTs}$ is stable even at $80^{\circ} \mathrm{C}$ for $2 \mathrm{~h}$. Thus a low rate of deactivation of the catalyst $\left(m-\mathrm{CH}_{3} \mathrm{PhO}\right)$ $\mathrm{TiCl}_{3} / \mathrm{CNTs}$ might be attributable to the enhanced steric hindrance of the support CNTs bond with $\left(m-\mathrm{CH}_{3} \mathrm{PhO}\right) \mathrm{TiCl}_{3}$. But the activity of catalyst $\left(m-\mathrm{CH}_{3} \mathrm{PhO}\right) \mathrm{TiCl}_{3} / \mathrm{MgCl}_{2}$ showed obviously decline for the copolymerization of ethylene with 1-hexene under the same conditions (Figure 1b). The polymer mass increases not linearity with increasing polymerization time within $2 \mathrm{~h}$ (Figure $1 \mathrm{~b}$ ). The discovery indicated that the support of CNTs is more efficient for non-metallocene catalyst for the copolymerization of ethylene with 1-hexene than $\mathrm{MgCl}_{2}$. The data recording started at temperature $80^{\circ} \mathrm{C}(\mathrm{t}=0 \mathrm{~min})$, before the temperature, the product mass was $1.9 \mathrm{~g}$ for line $\mathrm{a}^{\prime}$.

The HR-TEM image of the catalyst $\left(m-\mathrm{CH}_{3} \mathrm{PhO}\right) \mathrm{TiCl}_{3} / \mathrm{CNT}$ and low magnification TEM image of MWCNTs are shown in Figure 2. As shown in Figure 2, the CNTs have an outer average diameter of 30$60 \mathrm{~nm}$, multilayer arrays and many defects on the surface; exhibiting the nano template catalyst has a rough surface. It is believed that to some extent, the surface structure is damaged during the treatment with acid. The rough surface of the CNTs should be the result of the reaction between the functional group located on the surface and the transition metal compound $\left(m-\mathrm{CH}_{3} \mathrm{PhO}\right) \mathrm{TiCl}_{3}$, which is in favor of the attachment for the active sites for ethylene polymerization.

\section{Morphology of CNTs/PE nanocomposites particles}

HR-TEM result reveals that the polymeric shell covers around the CNTs core of the CNTs/PE nanocomposites particles. As ethylene was charged continuously in feed, the polymerization didn't quit within the polymerization time, the particle size increased with the polymerization time. It is about $35 \mathrm{~nm}$ at $2 \mathrm{~min}$ of polymerization time (Figure 3a), $70-80 \mathrm{~nm}$ at $10 \mathrm{~min}$ (Figure $3 \mathrm{~b}$ ) and $500 \mathrm{~nm}$ at $20 \mathrm{~min}$ (Figure 3c). It is interesting, the SEM images confirm that the CNTs/PE composite particles produced by the nano template catalyst $\left(m-\mathrm{CH}_{3} \mathrm{PhO}\right) \mathrm{TiCl}_{3} /$ CNTs, look like coral shape with about $8-10 \mu \mathrm{m}$ in diameter and about $30 \mu \mathrm{m}$ in length when the polymerization time is $120 \mathrm{~min}$ (Figure $3 \mathrm{~d})$. The SEM image of the cryo-fracture surface of the CNTs/PE nanocomposites is shown in Figure 3d. The sample in situ produced by $\left(m-\mathrm{CH}_{3} \mathrm{PhO}\right) \mathrm{TiCl}_{3} / \mathrm{CNTs} / \mathrm{AlEt}_{3}$ after $2 \mathrm{~min}$ of polymerization time exhibits a lot of nano fibers in PE matrix. The result reveals that CNTs of the CNTs/PE nanocomposites are well-distributed in PE matrix.

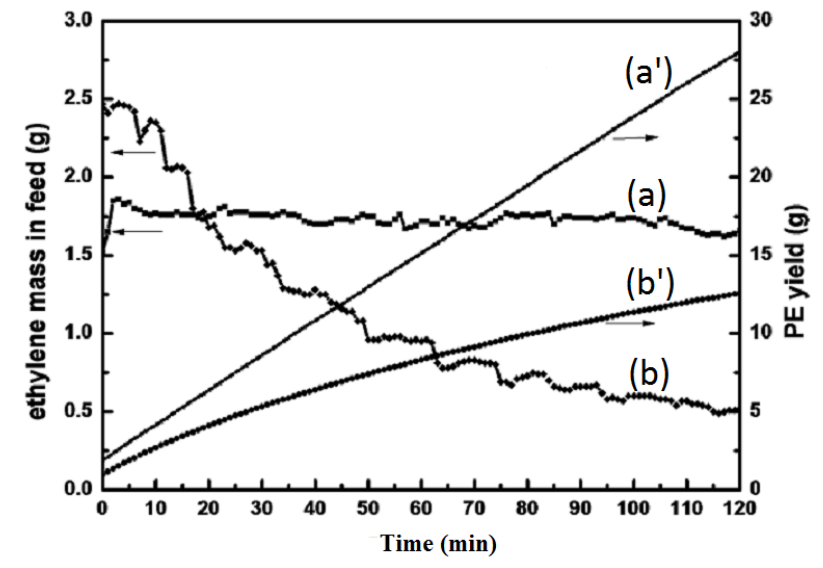

Figure 1: Ethylene mass in feed in polymerization catalyzed by catalyst systems of (a) $\left(m-\mathrm{CH}_{3} \mathrm{PhO}\right) \mathrm{TiCl}_{3} / \mathrm{CNTs}$ and (b) $\left(m-\mathrm{CH}_{3} \mathrm{PhO}\right) \mathrm{TiCl}_{3} / \mathrm{MgCl}_{2}, \mathrm{PE}$ yield obtained by catalyst systems of (a') $\left(m-\mathrm{CH}_{3} \mathrm{PhO}\right) \mathrm{TiCl}_{3} / \mathrm{CNTs}$ and (b') $\left(m-\mathrm{CH}_{3} \mathrm{PhO}\right) \mathrm{TiCl}_{3} / \mathrm{MgCl}_{2}$
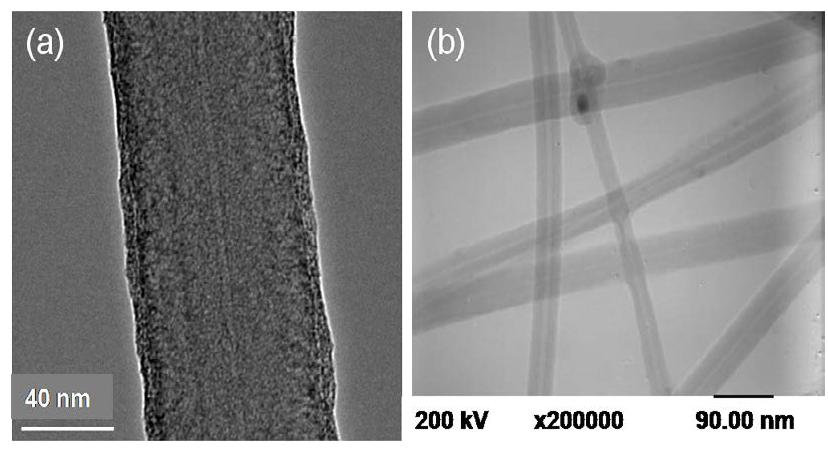

Figure 2: (a) HR-TEM image of the nano template catalyst of $\left(m-\mathrm{CH}_{3} \mathrm{PhO}\right)$ $\mathrm{TiCl}_{3} / \mathrm{CNTs}$ and (b) low magnification TEM image of MWCNTs
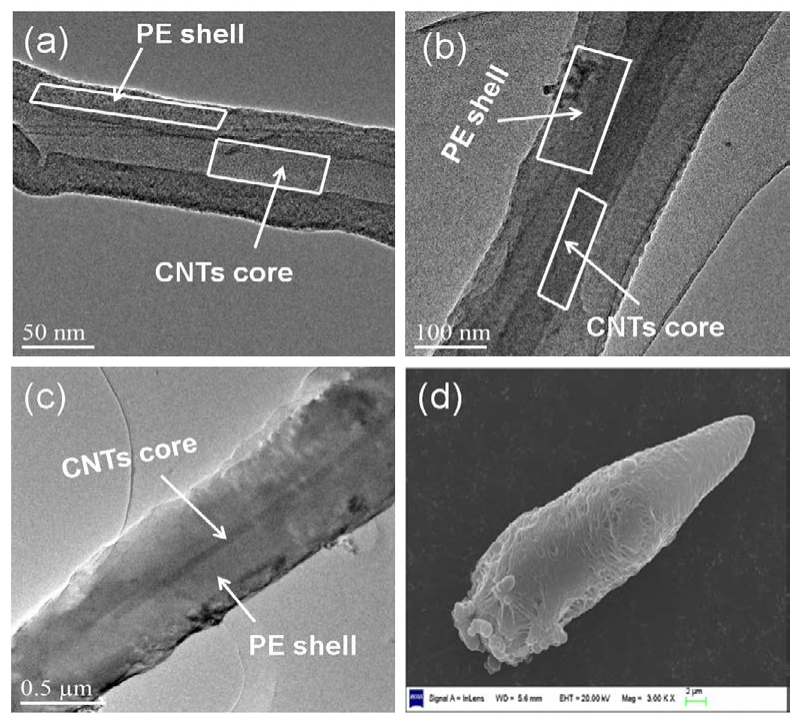

Figure 3: HR-TEM images of the CNTs/PE nanocomposites particles with polymerization time of (a) $2 \mathrm{~min}$, (b) $10 \mathrm{~min}$ and (c) $20 \mathrm{~min}$, and SEM image of the CNTs/PE nanocomposites particles with polymerization time of (d) 120 $\min$ 
Citation: Wang J, Guo J, Zhou Y, Huang Q, Jianjun Yi, et al.(2015) The Preparation of CNTs/PE Nanocomposites Particles with Coral Shape and Core-Shell Structure In Situ Produced via Nanotemplate Catalyst Based on MWCNTs. J Adv Chem Eng 5: 124. doi:10.4172/20904568.1000124

Page 4 of 5

The SEM micrographs taken from the cryo-fracture surfaces of coPE/CNTs nanocomposites samples are shown in Figure 4. Figure 4a shows the fracture surface of pure polyethylene which has a flat crack propagation region in addition to some wrinkle. But no CNTs can be seen on it. However, the coPE/CNTs nanocomposites sample in situ produced by the catalyst system $\left(m-\mathrm{CH}_{3} \mathrm{PhO}\right) \mathrm{TiCl}_{3} / \mathrm{CNTs} /$ $\mathrm{AlEt}_{3}$ after polymerization time of $2 \mathrm{~min}$, exhibiting a lot of nano CNTs in coPE matrix (Figure 4b). From Figure 4b, the distribution of the nano CNTs is fairly uniform. The result reveals that CNTs of the coPE/CNTs nanocomposites are well distributed in coPE matrix. With increasing polymerization time up to $10 \mathrm{~min}$, the size of coPE shell of the coPE/CNTs nanocomposites reaches about $75 \mathrm{~nm}$, coPE component is aggregated (Figure $4 \mathrm{c}$ ). When the polymerization time is $120 \mathrm{~min}$, the size of coPE shell of the coPE/CNTs nanocomposites is about $5 \mu \mathrm{m}$ (Figure $4 \mathrm{~d}$ ); the cryo-fracture surface of the coPE/CNTs nanocomposites sample is similar to that of pure PE.

TGA analyses were performed for both conventional polyethylene and PE/MWCNTs nanocomposites in Figure 5. From Figure 5 , it shows that conventional polyethylene and PE/MWCNTs nanocomposites have the same starting decomposition temperature of ca. $300^{\circ} \mathrm{C}$, the decomposition temperature of loss $5 \mathrm{wt} \%$ of them is ca. $360^{\circ} \mathrm{C}$. Furthermore, the conventional polyethylene and the PE/ MWCNTs nanocomposites have the similar sharp decomposition temperature at ca. $450^{\circ} \mathrm{C}$. The results indicate that the PE fraction of the PE/MWCNTs nanocomposites is thermally stable. From Figure 5, we can also find that for the conventional polyethylene, the complete decomposition temperature is $500^{\circ} \mathrm{C}$ (Figure 5a), while the $\mathrm{PE} /$ MWCNTs nanocomposites has approximately $75^{\circ} \mathrm{C}$ higher complete decomposition temperature at ca. $575^{\circ} \mathrm{C}$ (Figure 5b). MWCNTs can be decomposed at the temperature range from $500^{\circ} \mathrm{C}$ to $600^{\circ} \mathrm{C}$.

\section{Conclusion}

Nano template catalyst $\left(m-\mathrm{CH}_{3} \mathrm{PhO}\right) \mathrm{TiCl}_{3} / \mathrm{CNTs}$ was prepared through $\left(m-\mathrm{CH}_{3} \mathrm{PhO}\right) \mathrm{TiCl}_{3}$ bonded directly to the oxidized MWCNTs. The kinetics of the copolymerization of ethylene with 1-hexene catalyzed by the nano template catalyst revealed that the composite mass increased linearly with increasing of the polymerization time. CNTs/PE nanocomposites particles with coral-shaped and core-shell structure were formed in situ. CNTs of the CNTs/PE nanocompositess were well-distributed in the matrix confirmed by SEM.

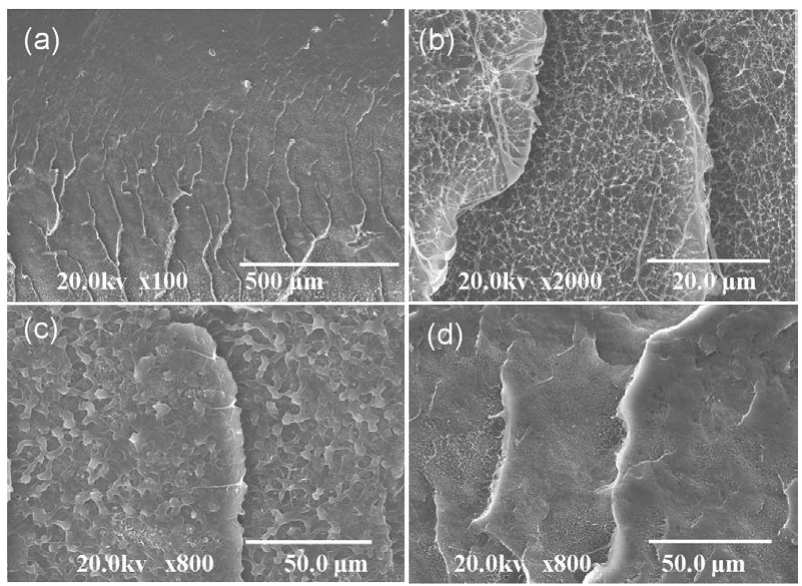

Figure 4: SEM images of cryo-fracture surfaces of (a) PE, and PE/CNTs nanocomposites after polymerization time of (b) $2 \mathrm{~min}$, (c) $10 \mathrm{~min}$ and (d) $120 \mathrm{~min}$

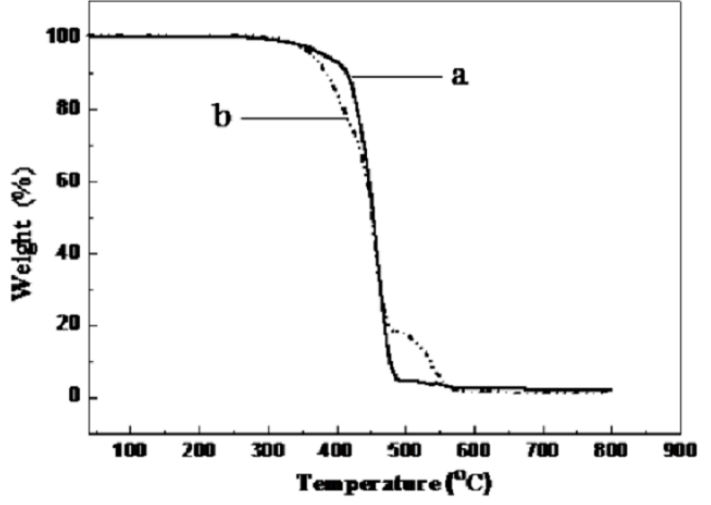

Figure 5: TGA weight loss curves of (a) conventional polyethylene and (b) polyethylene/MWCNTs nanocomposites.

\section{Acknowledgment}

We sincerely thank the National Natural Science Foundation of China (No. 21174011 and U1462102).

\section{References}

1. Fang Y, Xia W, He M, Liu BP, Hasebe K, et al. (2006) Novel $\mathrm{SiO}_{2}$-supported chromium catalyst bearing new organo-siloxane ligand for ethylene polymerization. Mol Catal A: Chem 247: 240-247.

2. Fink G, Steinmetz B, Zechlin J, Przybyla C, Tesche B (2000) Propene Polymerization with Silica-Supported Metallocene/MAO Catalysts. Chem Rev 100: 1377-1390.

3. Liu WJ, Huang QG, Yi JJ, Yang WT, Ma LF (2010) The Progress of the Catalysts for Olefins Coordination Polymerization. Polymer Bulletin (Chinese) 6: 1-33.

4. Delferro M, Marks JT (2011) Multinuclear Olefin Polymerization Catalysts. Chem Rev 111: 2450-2485.

5. Dong XC, Wang L, Sun TX, Zhou JF, Yang Q (2006) Study on ethylene polymerization catalyzed by $\mathrm{Cp} 2 \mathrm{ZrCl} 2 /$ carbon nanotube system. J Mol Catal A: Chem 255: 10-15.

6. Espinas J, Pelletier J, Szeto KC, Basset JM, Taoufika M (2014) Preparation and characterization of metallacalixarenes anchored to a mesoporous silica SBA-15 LP as potential catalysts. Microporous and Mesoporous Mater 188: 77-85.

7. Choi YY, Soares JBP (2010) Ethylene slurry polymerization using nickel diimine catalysts covalently-attached onto $\mathrm{MgCl}_{2}$-based supports. Polymer 51: 2271-2276.

8. Kong Y, Yi JJ, Huang QG, Yang WT (2010) With different structure ligands heterogeneous Ziegler-Natta catalysts for the preparation of copolymer of ethylene and 1-octene with high comonomer incorporation. Polymer 51: 3859 3866.

9. Wiemann K, Kaminsky W, Gojny FH, Schulte K (2005) Synthesis and Properties of Syndiotactic Poly(propylene)/Carbon Nanofiber and Nanotube Composites Prepared by in situ Polymerization with Metallocene/MAO Catalysts. Macromol Chem Phys 206: 1472-1478.

10. Huang YJ, Qin YW, Zhou Y, Niu H, Yu ZZ, et al. (2010) Polypropylene/Graphene Oxide Nanocomposites Prepared by In Situ Ziegler-Natta Polymerization. Chem Mater 22: 4096-4102.

11. Ye ZB, Alsyouri H, Zhu SP, Lin YS (2003) Catalyst impregnation and ethylene polymerization with mesoporous particle supported nickel-diimine catalyst. Polymer 44: 969-980.

12. Wu L, Lynch DT, Wanke SE (1999) Kinetics of Gas-Phase Ethylene Polymerization with Morphology-Controlled MgCl2-Supported TiCl4 Catalyst. Macromolecules 32: 7990-7998. 
Citation: Wang J, Guo J, Zhou Y, Huang Q, Jianjun Yi, et al.(2015) The Preparation of CNTs/PE Nanocomposites Particles with Coral Shape and Core-Shell Structure In Situ Produced via Nanotemplate Catalyst Based on MWCNTs. J Adv Chem Eng 5: 124. doi:10.4172/20904568.1000124

Page 5 of 5

13. Ko YS, Han TK, Park JW, Woo SI (1997) Copolymerization of ethylene-1Hexene over a thermally pretreated $\mathrm{MgCl} 2 / \mathrm{THF} / \mathrm{TiCl} 4$ bimetallic catalyst. $\mathrm{J}$ Polym Sci Part A: Polym Chem 35: 2769-2776.

14. Huang R, Liu D, Wang S, Mao BQ (2005) Preparation of spherical MgCl2 supported bis(imino)pyridyl iron(II) precatalyst for ethylene polymerization. J Mol Catal A: Chem 233(1-2): 91-97.

15. Xu R, Liu D, Wang S, Wang N, Mao B (2007) Preparation of spherical MgCl2supported bis(phenoxy-imine) zirconium complex for ethylene polymerization J Mol Catal A: Chem 263: 86-92.

16. Kanellopoulos V, Dompazis G, Gustafsson B, Kiparissides C (2004) Comprehensive Analysis of Single-Particle Growth in Heterogeneous Olefin Polymerization: The Random-Pore Polymeric Flow Model. Ind Eng Chem Res 43: 5166-5180.

17. Milani AM, Quijada R, Basso NRS, Graebin AP, Galland GB (2012) Influence of the graphite type on the synthesis of polypropylene/graphene nanocomposites. J Polym Sci Part A: Polym Chem 50: 3598-3605.

18. Pinheiro AC, Casagrande ACA, Casagrande OL (2014) Linear low-density polyethylene nanocomposites by in situ polymerization using a zirconium-nickel tandem catalyst system. J Polym Sci Part A: Polym Chem 52: 3506-3512.
19. Wang J, Yu MS, Jiang WH, Zhou Y, Li FJ, et al. (2013) The Preparation of Nanosized Polyethylene Particles via Carbon Sphere Nanotemplates. J Ind Eng Chem Res 52: 17691-17694.

20. Conley MP, Delley MF, Siddiqi G, Lapadula G, Copéret C (2014) Polymerization of Ethylene by Silica-Supported Dinuclear CrIII Sites through an Initiation Step Involving C[BOND]H Bond Activation. Angew Chem Int Ed 53: 1872-1876.

21. Shen XR, Hu J, Fu ZS, Lou JQ, Fan ZQ (2013) Counting the number of active centers in $\mathrm{MgCl}$-supported Ziegler-Natta catalysts by quenching with 2-thiophenecarbonyl chloride and study on the initial kinetics of propylene polymerization. Catal Commun 30: 66-69.

22. Carman CJ, Harrington RA, Wilkes CE (1977) Monomer Sequence Distribution in Ethylene-Propylene Rubber Measured by ${ }^{13} \mathrm{C}$ NMR. 3. Use of Reaction Probability Model. Macromolecules 10: 536-544.

23. Kimura K, Yuasa S, Maru Y (1984) Carbon-13 nuclear magnetic resonance study of ethylene-1-octene and ethylene-4-methyl-1-pentene copolymers. Polymer 25: 441-446.

24. He T, Jia S, Jiang $P$, Chen $Y$ (2006) Solid state 13c-nmr study of $\gamma$-irradiated poe. Acta Polymerica Sinica 4: 624-626. 